\title{
Forced oscillation measurements do not affect upper airway muscle tone or sleep in clinical studies
}

\author{
J.R. Badia*, R. Farré", J. Rigau*, M.E. Uribe*, D. Navajas", J.M. Montserrat*
}

Forced oscillation measurements do not affect upper airway muscle tone or sleep in clinical studies. J.R. Badia, R. Farré, J. Rigau, M.E. Uribe, D. Navajas, J.M. Montserrat. C) ERS Journals Ltd 2001.

ABSTRACT: Upper airway obstruction in the sleep apnoea/hypopnoea syndrome (SAHS) can be easily assessed by measuring respiratory impedance with the forced oscillation technique (FOT). This methodology has been proposed as a useful clinical tool both for the diagnosis of sleep breathing disorders and for continuous positive airway pressure (CPAP) titration. However, previous studies suggest that the application of high-frequency pressure oscillation to the upper airway may induce changes in the electroencephalogram (EEG) or upper airway muscle function. The effect of FOT measurements on upper airway muscle tone and EEG in clinical sleep studies was examined. Seven patients with moderate SAHS were included (age: $54 \pm 11$ yrs; apnoea/hypopnoea index: $43 \pm 21$ events $\cdot h^{-1}$; body mass index: $30 \pm$ $2 \mathrm{~kg} \cdot \mathrm{m}^{-2}$ ). Genioglossus surface electromyogram activity (EMGgg) and EEG signal were analysed with and without FOT application (frequency: $5 \mathrm{~Hz}$ and $30 \mathrm{~Hz}$; peak-topeak pressure oscillation: $1 \mathbf{c m H}_{2} \mathrm{O}$ ) during stable sleep. Measurements were carried out in two different situations. Step 1: applying FOT during episodes of obstructive events or flow limitation; and step 2: during prolonged periods of normal breathing at optimal CPAP. The root mean square of EMGgg activity and fast Fourier analysis (alpha and delta bands) of the EEG signal were performed.

The application of FOT did not increase EMGgg activity in any of the situations studied. In addition, no evidence of the effects on EEG was found: alpha/delta relationship: awake:0.70, baseline sleep:0.13, FOT(5 Hz):0.18, FOT(30 Hz):0.11.

The presented results suggest that the use of forced oscillation technique over the ranges of frequency and amplitude proposed for clinical sleep studies does not induce changes in upper airway muscle activity and neurological variables in patients with sleep apnoea/hypopnoea syndrome.

Eur Respir J 2001; 18: 335-339.
*Servei de Pneumologia i Allèrgia Respiratòria, Hospital Clínic, Barcelona, Spain. \# Institut Clínic de Pneumologia i Cirurgia Toràcica (ICPCT), Hospital Clínic de Barcelona and Laboratori de Biofísica i Bioenginyeria, Facultat de Medicina, Universitat de Barcelona, Barcelona, Spain.

Correspondence: J.M. Montserrat, Servei de Pneumologia i Allèrgia Respiratòria, Hospital Clínic, Villarroel 170, 08036 Barcelona, Spain.

Fax: 932275454

Keywords: Electromyography forced oscillation technique respiratory impedance respiratory resistance upper airway function upper airway reflexes.

\section{Received: September 282000}

Accepted after revision March 202001

This study was supported by grants CICYT (SAF99-0001), DGESIC (PM980027) and SEPAR 1999.
The forced oscillation technique (FOT) is a simple and noninvasive method that allows continuous online monitoring of airflow obstruction during sleep, even in the absence of flow, as occurs in apnoeas. FOT has been applied in clinical diagnostic studies in patients with sleep apnoea/hypopnoea syndrome (SAHS) [1-4] and in continuous positive airway pressure (CPAP) titration studies [5,6] with highly encouraging results.

The upper airway is a complex structure with functional properties that are still poorly understood. Reflexes in response to pressure changes may play an important role in maintaining upper airway patency within the breathing cycle during sleep [7-10]. The effect of high-frequency oscillating pressures has been previously studied mainly in animals, but also in the sleeping human [11-14]. In experimental conditions, high-frequency oscillation appeared to elicit an increase in upper airway muscle activity. The mechanism could be a direct activation of local receptors with an input on muscle activity. However, methodological artefacts must also be considered as they are not easy to avoid and may lead to nonvisible sleep fragmentation and neurological arousal [14]. Upon applying FOT extensively in sleep studies, an investigation was designed to verify that the low-frequency and lowamplitude oscillations applied in routine measurements of airway obstruction do not have any effect on upper airway patency, upper airway muscle electromyography and electroencephalogram (EEG) in a clinical setting in patients with moderate-to-severe sleep apnoea syndrome.

\section{Methods}

Seven male patients with a previous recent diagnosis by full polysomnography (PSG) of moderateto-severe SAHS (age: $54 \pm 11$ yrs; apnoea/hypopnoea index: $43 \pm 21$ events $\cdot \mathrm{h}^{-1}$; body mass index: $30 \pm$ $2 \mathrm{~kg} \cdot \mathrm{m}^{-2}$ ) were studied. This study was approved by the Human Ethics Committee of the Hospital Clínic. Informed written consent was obtained from all subjects. The studies were conducted under a CPAP 
conventional PSG setting, including continuous monitoring of the EEG (O4/A1, C3/A2), genioglossus electromyogram (EMGgg) and electro-oculogram for sleep staging according to standard criteria. Arterial oxygen saturation was measured continuously with a finger probe using a pulse oxymeter (504 Critical Care Systems, Inc., Waukesha, WI, USA). Ribcage and abdominal motion were monitored by bands placed over the thorax and abdomen (effort belts; 5703-X, Nellcor Puritan Benett Inc., Minneapolis, MN, USA). Airflow was assessed using a Fleisch-type pneumotachograph located between the nasal mask and a conventional leak valve and connected to a differential pressure transducer $\left( \pm 2 \mathrm{cmH}_{2} \mathrm{O}\right.$; MP54, Validyne, Northridge, CA, USA). Nasal pressure was obtained from one of the outlets of the mask and measured with a similar pressure transducer $\left( \pm 22 \mathrm{cmH}_{2} \mathrm{O}\right.$; MP45, Validyne). These signals were recorded continuously on a polygraph (SleepLab 1000P, Jaëger, Germany). Sleep stage was determined according to the criteria of RECHTSCHAFFEN and KALES [15], and the presence of arousal was defined according to the recommendations of the American Sleep Disorders Association [16]. Microarousals were identified following the same criteria, but lasting $\geqslant 1.5 \mathrm{~s}$ and associated with EMGgg activity $[17,18]$. In addition, an EEG signal analysis was performed by means of a fast Fourier frequency analysis of the signal $[19,20]$. EMGgg was recorded using surface electrodes placed medially above and below the chin. The raw electromyogram (EMG) signals were acquired with a P55 A.C. Pre-Amplifier (Grass Instrument Co., West Warwick, RI, USA), band pass filtered at $30-1,000 \mathrm{~Hz}$, and amplified and digitized at a sampling rate of $2,500 \mathrm{~Hz}$. The EEG signal, EMGgg, airflow and CPAP pressure were also recorded and stored for further analysis in a CODAS system (Dataq Instruments Inc. Akron, OH, USA).

\section{Stimulus}

The oscillating pressure stimulus was a pressure wave generated with the same basic setting that the present group has described in FOT guided CPAP titration studies [1-3]. This setting allowed the application of a CPAP device to normalize sleep variables. The high-frequency oscillating pressure of $1 \mathrm{cmH}_{2} \mathrm{O}$ of amplitude peak-to-peak was generated by a loudspeaker. In clinical studies, the amplitude is usually set at $1 \mathrm{cmH}_{2} \mathrm{O}$ and oscillation frequency at $5 \mathrm{~Hz}$, since in a model study [1] this frequency optimized the sensitivity of the system to obstruction as well as time resolution. However, in this investigation $5 \mathrm{~Hz}$ as well as $30 \mathrm{~Hz}$ were tested at the same pressure amplitude of $1 \mathrm{cmH}_{2} \mathrm{O}$. With this setting, both oscillation and CPAP pressure could be turned on or off automatically by the investigator from outside the patient's room. Therefore, the setting could be considered noiseless, thus minimizing possible environment-related arousal and methodological artefacts.

\section{Protocol}

All subjects arrived at the sleep unit $\geqslant 8 \mathrm{~h}$ before the beginning of the study. They were trained with CPAP and the best fitting mask was chosen. Once the setting was implemented and tested, awake maximal values of EMGgg were recorded and activity with voluntary contraction manoeuvres (tongue protrusion against resistance) were verified. All subjects were then allowed to sleep in their preferred position. No stimuli were applied until a stable sleep state was achieved (phase II or delta sleep for 10 min despite existence of transient arousal secondary to obstructive events). All patients were studied in nonrapid eye movement sleep. Oscillation stimuli were applied in the following twostep procedure. Step 1: during obstructive events and/ or flow limitation periods; and step 2: continuously during a period of $20 \mathrm{~s}$ under optimal CPAP with absence of flow limitation.

\section{Analysis}

EMGgg activity was calculated as the root mean square (RMS) of the raw signal and expressed in arbitrary units (mean $\pm \mathrm{SD}$ ). During the obstructive events or flow limited periods, the RMS of the breath with oscillation was compared with the mean of the RMS of the breath before oscillation application and the breath following the stimulus. During the periods of CPAP, the EMGgg RMS with pressure oscillation was compared with the EMGgg RMS of a period of the same length prior to the oscillation application. At least four applications were performed in each situation studied (16 applications for each subject: $5 \mathrm{~Hz}$ and $30 \mathrm{~Hz}$, obstructive events and optimal CPAP). The results for each baseline or stimulation value are the mean of the four trials. The individual percentage of change between baseline and pressure oscillation stimuli was calculated for each of the four trials and, finally, the mean of these percentages of change was calculated.

A visual review of the EEG signal was performed. To complete the evaluation of the EEG, a fast Fourier spectral analysis of the signal was performed, comparing the amplitude of the alpha $(8-12 \mathrm{~Hz})$ and delta $(0.2-4 \mathrm{~Hz})$ bands of the signal with and without FOT applied at optimal CPAP with absence of flow limitation (step 2). Paired t-tests were used to compare baseline and stimuli results at both frequencies. Tests were assumed to be significant at $\mathrm{p}<0.05$.

\section{Results}

Pressure oscillation, at $5 \mathrm{~Hz}$ and $30 \mathrm{~Hz}$, was applied during obstructive events as well as at optimal CPAP. A visual review of the trace of EMGgg and EEG did not show any changes in genioglossus activity induced by forced oscillation. The RMS of the EMGgg signal was performed confirming the visual results. Data for each patient with both frequencies in the two situations of application are detailed in table 1 . The mean absolute changes in EMGgg activity (expressed 
Table 1. - Summary of root mean square (RMS) of genioglossus electromyogram (EMGgg) activity

\begin{tabular}{|c|c|c|c|c|c|c|c|c|c|c|c|c|c|}
\hline \multirow[t]{2}{*}{ Subjects } & \multirow{2}{*}{$\begin{array}{c}\text { EMGgg } \\
\text { max. }\end{array}$} & \multicolumn{6}{|c|}{ Obstructive events } & \multicolumn{6}{|c|}{ Optimal CPAP } \\
\hline & & Baseline & $5 \mathrm{~Hz}$ & $\begin{array}{c}\% \\
\text { change }\end{array}$ & Baseline & $30 \mathrm{~Hz}$ & $\begin{array}{c}\% \\
\text { change }\end{array}$ & Baseline & $5 \mathrm{~Hz}$ & $\begin{array}{c}\% \\
\text { change }\end{array}$ & Baseline & $30 \mathrm{~Hz}$ & $\begin{array}{c}\% \\
\text { change }\end{array}$ \\
\hline 1 & 0.76 & 0.070 & 0.067 & -2.0 & 0.060 & 0.059 & -1.0 & 0.030 & 0.030 & -2.0 & 0.035 & 0.035 & 0 \\
\hline 2 & 1.00 & 0.050 & 0.049 & -1.3 & 0.044 & 0.044 & 0 & 0.036 & 0.040 & 2.0 & 0.040 & 0.041 & 1.8 \\
\hline 3 & 0.76 & 0.060 & 0.060 & 0.4 & 0.051 & 0.050 & -0.2 & 0.024 & 0.024 & -0.4 & 0.024 & 0.025 & 6.0 \\
\hline 4 & 0.63 & 0.051 & 0.051 & 0.46 & 0.045 & 0.043 & -5.0 & 0.040 & 0.040 & -0.4 & 0.041 & 0.039 & -3.9 \\
\hline 5 & 0.63 & 0.092 & 0.088 & -6.0 & 0.097 & 0.097 & 0.4 & 0.070 & 0.070 & 0 & 0.069 & 0.069 & -0.9 \\
\hline 6 & 0.67 & 0.065 & 0.065 & 0.17 & 0.065 & 0.067 & 4.0 & 0.046 & 0.046 & 0 & 0.046 & 0.046 & 0.35 \\
\hline 7 & 0.45 & 0.063 & 0.055 & -11.0 & & & & 0.055 & 0.053 & -4.0 & 0.053 & 0.050 & -4.0 \\
\hline Mean & 0.702 & 0.064 & 0.061 & -2.750 & 0.060 & 0.061 & -0.300 & 0.043 & 0.043 & -0.610 & 0.044 & 0.043 & -0.030 \\
\hline
\end{tabular}

RMS EMGgg is expressed in arbitrary units. CPAP: continuous positive airway pressure.

as a percentage) during obstructive events were $-2.75 \pm 7 \%(5 \mathrm{~Hz})$ and $-0.30 \pm 5 \%(30 \mathrm{~Hz})$. A representative example of the application of FOT during apnoea can be seen in figure 1. The pressure oscillation did not result in restoration of airflow or have any effect on the length of obstructive events in any case. FOT was also applied during inspiration in flow limitation periods without effects on EMGgg or EEG. An example can be seen in figure 2. Finally, figure 3 shows the lack of effect on these signals of prolonged application of FOT under optimal CPAP.

The visual review of the EEG signal showed that FOT did not appear to elicit arousal or microarousal. Further analysis of EEG with the fast Fourier transformation was carried out, analysing the two channels of EEG and comparing the $20 \mathrm{~s}$ prior to stimulation with the following $20 \mathrm{~s}$ under continuous FOT application in stable sleep at optimal CPAP. With this analysis, no evidence of the effects on EEG was found:

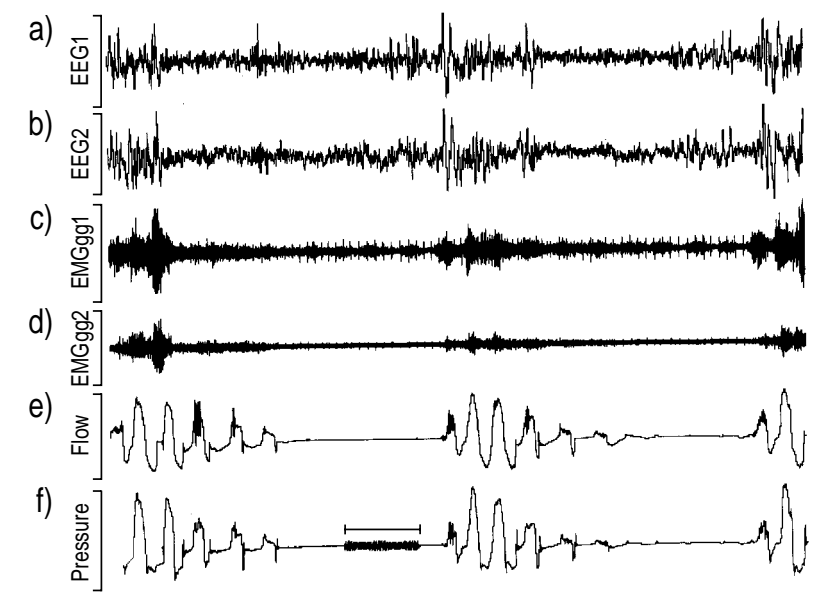

Fig. 1.-Compressed polysomnographic tracing from a patient with sleep apnoea/hypopnoea syndrome. a) and b) show 2 channels of electroencephalogram (EEG). c) and d) show genioglossus electromyogram (EMGgg1) and sternocleidomastoid electromyogram (EMGgg2), respectively. e) and f) show flow (pneumotachograph) and pressure at the nasal mask respectively. Application of forced oscillation during obstructive apnoeas; the oscillation at a frequency of $5 \mathrm{~Hz}$ can be seen in the pressure signal in the first of two consecutive apnoeas. Forced oscillation technique (FOT) did not result in an increase in EMGgg activity or affect the length of obstructive events. The horizontal bar in $\mathrm{f}$ ) indicates application of FOT during $8 \mathrm{~s}$. alpha/delta sleep relationship awake:0.70; baseline sleep:0.13; FOT(5 Hz):0.18; FOT(30 Hz):0.11. Figure 4 shows absolute results of the alpha/delta ratio in baseline sleep and under stimulation at 5 and $30 \mathrm{~Hz}$ for the two EEG channels analysed.

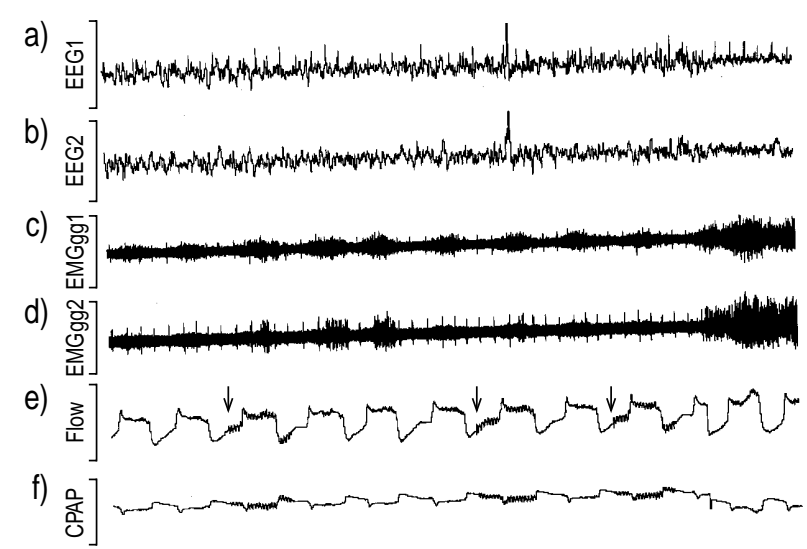

Fig. 2.-Conditions of flow limitation at suboptimal continuous positive airway pressure (CPAP). During hypopnoea forced oscillation technique (FOT) is applied briefly in inspiration without any significant effect on a) and b) electroencephalogram (EEG) or c) and d) electromyogram (EMG). Arrows indicate FOT.

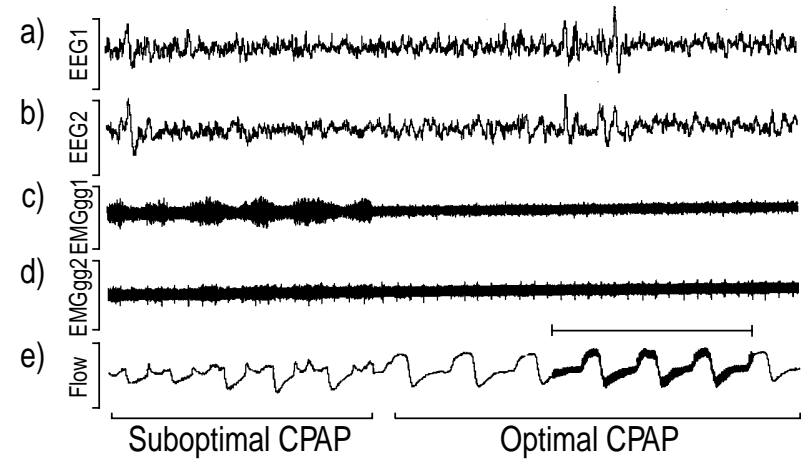

Fig. 3.-Prolonged application of forced oscillation technique (FOT) at optimal continuous positive airway pressure (CPAP). The electromyogram (EMG) signal in c) and d) shows an increased activity during obstructed breathing at suboptimal CPAP. Once optimal treatment pressure is achieved the EMG activity (c) and d)) decreases to the minimum. The horizontal bar in e) indicates application of FOT during 15 s. EEG: electroencephalogram. 


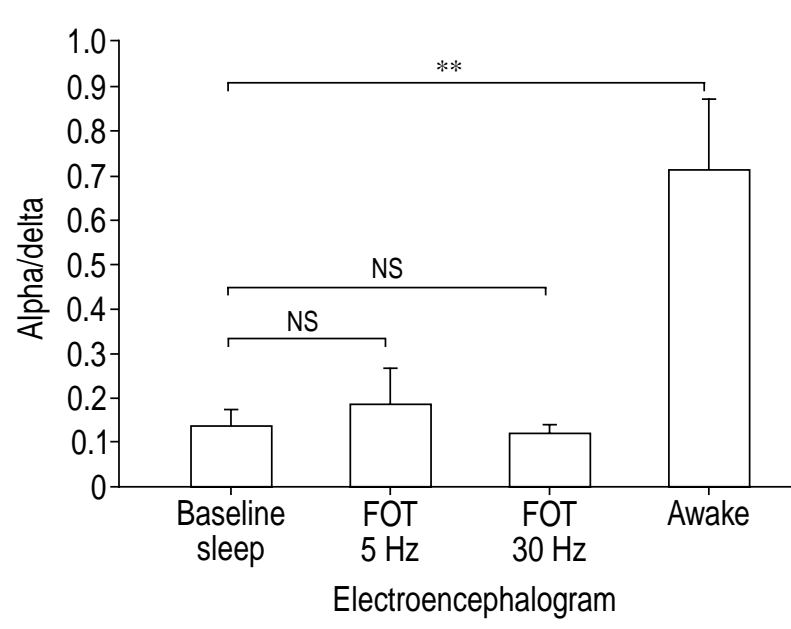

Fig. 4. - Electroencephalogram analysis with the fast Fourier transformation comparing the $20 \mathrm{~s}$ prior to stimulation with the following $20 \mathrm{~s}$ under continuous forced oscillation technique (FOT) application in stable sleep at optimal continuous positive airway pressure. Error bars: SEM. NS: nonsignificant. $* *$ : $\mathrm{p}<0.01$.

\section{Discussion}

In this study, high-frequency oscillation did not result in any increase in EMGgg activity or promote resolution of upper airway obstruction. Frequency analysis of the EEG signal was carried out and no evidence of neurological activation was found. These findings are consistent with the clinical experience with FOT [3-5]. Significant effects on the upper airway or the EEG produced by the use of FOT, with and without CPAP, were not observed in subjects with SAHS. However, previous research was designed to assess the applicability of FOT in sleep studies, and did not focus specifically on possible effects of highfrequency pressure oscillation on the upper airway.

This lack of effect of forced oscillation on upper airway muscle activity can be considered, to some extent, as contradictory to results from other groups. Most of these previous studies were carried out in chronically tracheostomized dogs [11-13]. These experimental conditions are very different from clinical sleep studies in the human. However, Henke and Sulbivan [14] have shown evidence of EMG activation in the sleeping human, both in healthy subjects and in patients with obstructive sleep apnoea [14]. The presence of arousal or microarousals leading directly to upper airway muscle activation could be a possible explanation for these divergent results. In this study, trials that promoted immediate arousal were discarded, but trials in which arousal occurred shortly after stimulation were included in the analysis. In fact, the possibility that the responses observed are due to brief arousal is clearly pointed out by the authors. The present setting is believed to have improved the previous methodology, as it was completely automated. Forced oscillation was applied smoothly with a noiseless loudspeaker, and all the equipment was handled remotely from another room, thus minimizing possible methodological artefacts and the possibility of arousal. As a result, during the present investigations visible arousal or microarousal after the application of the forced oscillations were absolutely uncommon. Frequency analysis with the fast Fourier transformation confirmed that neurological activation was not present. Thus, in the absence of arousal and microarousals no evidence of direct effects of FOT on the upper airway muscles was found. In this investigation, surface EMG electrodes, which can be considered to be less sensitive than invasive wire electrodes, were used. However, it is felt that the quality of the signals obtained in the present study allows for a reliable interpretation. As can be seen in the figures provided, the electrodes accurately tracked EMG activation, not only during maximum voluntary contraction manoeuvres, but also at suboptimal CPAP and during snoring.

For the purposes of this study the effect of forced oscillations was examined at a frequency of $5 \mathrm{~Hz}$ and an amplitude of $1 \mathrm{cmH}_{2} \mathrm{O}$. These values have been found to provide the optimal balance between sensitivity to airflow obstruction and time resolution, and they are proposed for clinical studies [1]. In addition, $30 \mathrm{~Hz}$ was also tested in order to reproduce the methodology of the study of Henke and Suldivan. [14]. It is clear that larger pressure swings applied to the upper airway will cause increased activation of local mechanoreceptors and afferent pathways. In fact, all published animal model studies that demonstrate muscle activation applied a larger pressure amplitude than in the present study, ranging 2-4 $\mathrm{cmH}_{2} \mathrm{O}$. It would be interesting to test a broader range of frequencies and amplitudes in order to identify thresholds of responses. However, this was beyond the scope of the present study as the aim was to test the clinical validity of FOT for sleep studies.

Another potential limitation of the present study may relate to the included population. All patients had moderate-to-severe sleep apnoea and had not been treated previously with CPAP. In addition, all were overweight or presented with obesity. These two conditions have been associated with impaired responses of the upper airway to diverse stimuli [21, 22]. Thus, it is possible that these patients could have a higher response threshold to the high-frequency pressure oscillation stimulus. Answering this question will require further investigation of a significant sample from the normal population.

When forced oscillation pressure is applied during apnoea the stimulus reaches only the upper airway above the point of obstruction. The present study was designed to include obstructed and nonobstructed breathing under optimal CPAP. Trials at optimal CPAP were included for two reasons. Firstly, in a previous study it was found that the measure of airflow obstruction obtained by means of FOT could be used for CPAP titration. Secondly, under optimal CPAP, the pressure oscillation is applied to the entire airway and thus could stimulate mechanoreceptors located below the site of obstruction. The presented findings were consistent and no evidence of upper airway muscle activation was found in any of the situations studied.

The results of this study show that the forced oscillation technique applied to assess airflow obstruction, 
as proposed for clinical studies, does not increase upper airway muscle tone or result in neurological activation in patients with sleep apnoea/hypopnoea syndrome.

Acknowledgements. The authors wish to thank A.G. Ten Have for her assistance in the electroencephalogram analysis and M. Puig for her technical assistance.

\section{References}

1. Farré R, Peslin R, Rotger M, Navajas D. Inspiratory dynamic obstruction detected by forced oscillation during CPAP. A model study. Am J Respir Crit Care Med 1997; 155: 952-956.

2. Farré R, Rotger M, Montserrat JM, Navajas D. A system to generate simultaneous forced oscillation and continuous positive airway pressure. Eur Respir $J$ 1997; 10: 1349-1353.

3. Navajas D, Farré R, Rotger M, Badia JR, Puig-deMorales M, Montserrat JM. Assesment of airflow obstruction during CPAP by means of forced oscillation in patients with sleep apnea. Am J Respir Crit Care Med 1998; 157: 1526-1530.

4. Badia JR, Farré R, Montserrat JM, et al. Forced oscillation technique for the evaluation of the sleep apnoea hypopnoea syndrome. A pilot study. Eur Respir J 1998; 11: 1-7.

5. Badia JR, Farré R, Kimoff RJ, et al. Clinical application of the forced oscillation technique for CPAP titration in the sleep apnea/hypopnea syndrome. Am J Respir Crit Care Med 1999; 160: 1550-1554.

6. Lorino AM, Lofaso F, Uizabo D, et al. Respiratory resistive impedance as an index of airway obstruction during nasal continuous positive airway pressure titration. Am J Respir Crit Care Med 1998; 158: $1465-1470$.

7. Issa FG, Edwards P, Szeto E, Lauff D, Sullivan C. Genioglossus and breathing responses to airway occlusion: effect of sleep and route of breathing. J Appl Physiol 1998; 64: 543-548.

8. Mathew OP, Abu-Osba YK, Thach BT. Influence of upper airway pressure changes on genioglossus muscle respiratory activity. J Appl Physiol 1982; 52: 438-444.

9. Kimoff RJ, Cheong TH, Olha AE, et al. Mechanisms of apnoea termination in obstructive sleep apnea: role of chemoreceptor and mechanoreceptor stimuli. Am J Respir Crit Care Med 1994; 149: 707-714.
10. Remmers JE, DeGroot WJ, Sauerland EK, Anch AM. Pathogenesis of upper airway occlusion during sleep. J Appl Physiol 1978; 44: 931-938.

11. Plowman LD, Lauff DC, Berthon Jones M, Sullivan CE. Waking and genioglossus muscle responses to upper airway pressure oscillation in sleeping dogs. J Appl Physiol 1990; 68: 2564-2573.

12. Zhang S, Mathew OP. Response of laryngeal mechanoreceptors to high-frequency pressure oscillation. J Appl Physiol 1992; 73: 219-223.

13. Eastwood PR, Satoh M, Curran AK, Zayas MT, Smith CA, Dempsey JA. Inhibition of inspiratory motor output by high-frequency low-pressure oscillations in the upper airway of sleeping dogs. $J$ Physiol 1999; 517: 259-271.

14. Henke KG, Sullivan CE. Effects of high-frequency oscillating pressures on upper airway muscles in humans. J Appl Physiol 1993; 75: 856-862.

15. Rechtschaffen A, Kales A, eds. U.S. Public Health Services. A manual of standardized terminology, techniques, and scoring system for sleep stages of human subjects. Washington D.C., U.S. Government Printing Office, 1963.

16. EEG arousals: scoring rules and examples: a preliminary report from The Sleep Disorders Atlas Task Force of the American Sleep Disorders Association. Sleep 1992; 15: 174-184.

17. Davies RJ, Belt PJ, Robert SJ, Ali NJ, Stradling JR. Arterial blood pressure responses to graded transient arousal from sleep in normal humans. $J$ Appl Physiol 1993; 74: 1123-1130.

18. Pitson D, Chhina N, Knijn S, Van Heerwarden M, Stradling JR. Changes in pulse transit time and pulse rate as markers of arousal from sleep in normal subjects. Clin Sci 1994; 87: 269-273.

19. Martin SE, Wraith PK, Deary IJ, Douglas NJ. The effect of nonvisible sleep fragmentation on daytime function. Am J Respir Crit Care Med 1997; 155: 15961601.

20. Alloway CDE, Ogilvie RD, Shapiro CM. EEG spectral analysis of the sleep-onset period in narcoleptics and normal sleepers. Sleep 1999; 22: 191-203.

21. Larsson H, Carlsson-Nordlander B, Lindblad LE, Norbeck O, Svanborg E. Temperature thresholds in the oropharinx of patients with obstructive sleep apnea syndrome. Am Rev Respir Dis 1992; 146: $1246-1249$

22. Deegan PC, Mulloy E, McNicholas WT. Topical oropharyngeal anesthesia in patients with obstructive sleep apnea. Am J Respir Crit Care Med 1995; 151: 1108-1112. 